\title{
EL IMPACTO DE LAS POLÍTICAS DE PRIVATIZACIÓN DURANTE LOS AÑOS NOVENTA: TRANSMISIÓN DEL LEGADO CULTURAL EN EL BARRIO BELGRANO DE LA CIUDAD DE ROSARIO (SANTA FE) Y SUS ALCANCES EN LAS ORGANIZACIONES ESCOLARES
}

\author{
Natalia Jorgelina Forlini (Universidad Nacional de Rosario - \\ Consejo Nacional de Investigaciones Científicas yTécnicas)* \\ nataliaforlini@hotmail.com
}

Recibido: 28/07/2012 Aceptado: 11/10/2012

\begin{abstract}
Resumen
El presente trabajo intenta indagar acerca del impacto de las políticas de privatización en la década del noventa en el tejido social del Barrio Belgrano de la ciudad de Rosario y sus posibles alcances en las organizaciones escolares. A tal fin, partiendo de los postulados de la micro- historia reciente y tomando como herramientas fuentes orales y documentales, se propone analizar: por un lado, ciertas continuidades y rupturas que habría producido tal proceso, por otro, la configuración identitaria del barrio conformado en sus orígenes en torno al ferrocarril Mitre, y por último, el proceso de transmisión del legado cultural en el ámbito escolar. Asimismo, se intenta dar cuenta de las relaciones históricas que se establecieron entre la denominada memoria social y su transmisión, atendiendo a la circulación social del legado cultural.
\end{abstract}

\section{Palabras clave}

Políticas de privatización - Identidad barrial - Legado cultural - Historia escolar - Transmisión.

\section{Abstract}

This paper attempts to inquire about the impact of privatization policies in the nineties in the social fabric of Belgrano district of the city of Rosario and its possible scope in school organizations. To this end, based on the principles of the micro-recent

* Licenciada y Profesora en Ciencias de la Educación. Universidad Nacional de Rosario. Becaria Tipo II del Consejo Nacional de Investigaciones Científicas y Técnicas. Profesora de la carrera Ciencias de la Educación. Universidad Nacional de Rosario. 
history and taking as tools oral and documentary sources, trying to assess: first, certain continuities and ruptures that would have produced such a process, on the other, the identity of the neighborhood configuration formed originally around the Mitre railroad, and finally, the process of transmission of cultural heritage in the school. It also attempts to account for the historical relations established between the so called social memory and its transmission, considering the social circulation of cultural heritage.

\section{Key words}

Privatization policy - Neighborhood identity - Cultural legacy - School history Transmission.

\section{Introducción a la problemática}

El presente trabajo (1) forma parte de un proyecto de investigación más amplio, el cual gira en torno a la relación de la escuela con la comunidad barrial en la segunda mitad del siglo XX. El objetivo general es abordar la transmisión de cánones culturales en la escuela, analizando el impacto en la identidad de los pobladores. La unidad de análisis comprende la delimitación de un barrio de la ciudad de Rosario, provincia de Santa Fe, denominado "barrio Belgrano".

En este caso en particular, se seleccionó el período que comprende la década del 90' y para tal fin, se utilizaron las herramientas de la microhistoria socio- cultural y educativa. Si bien el análisis se circunscribe a procesos barriales propios de este sector poblacional (nivel micro social), esto no invalida el correlato con procesos a nivel macro social involucrados en este estudio. Es decir, las categorías utilizadas permiten el entrecruzamiento de los dos niveles de determinación: el micro-social y el macro-social. De igual manera, este tipo de enfoque posee características y perspectivas propias. En este sentido, se buscó reconstruir las cadenas de causalidades que, a partir de los datos recogidos, producen las formas sociales que se observaron (Rosental, 1998).

Al realizar un estudio recortado temporalmente en la década de 1990, se suscitan preguntas vinculadas a los debates acerca de los estudios de la historia reciente: cómo pensar la historia recientemente vivida, de qué modo se entrelazan con el historiador los relatos de quienes dan testimonio de sus vivencias y qué resignificación de la historia de los protagonistas elabora ese historiador, por citar sólo algunas. Se entiende que un criterio cerrado y centrado meramente en lo cronológico o en los aspectos metodológicos no explica qué es la historia reciente, además no resuelve la problemática acerca de la superioridad o no de la memoria por sobre la historia (Traverso, 2007).

Para el análisis micro-social, una de las fuentes de información que se utilizó fueron los testimonios de los sujetos involucrados. Como transmisión de la historia oral, los "protagonistas" cuentan su historia, también aquella ligada al barrio, jugando un papel central la memoria de quienes narran. La memoria, 
que se conjuga siempre con lo colectivo, se presenta como esa "construcción simbólica y elaboración de sentidos sobre el pasado" (Franco, Levin, 2007: 40). Se desarrolla, entonces, en dos dimensiones que se vinculan entre sí: una, en relación a procesos subjetivos y por lo tanto privada, y la otra, de carácter público, de apropiación de lo social y colectivo (Traverso, 2007), esto último denominado memoria social. Los relatos de quienes viven en el barrio, y que conforman la historia oral, posibilitan reconstruir el pasado. No obstante, son representaciones de vivencias pretéritas que permiten ser reflexionadas y no constituyen una copia fiel del pasado, sino que el mismo se reconstruye a través de ellos.

Con fines metodológicos, se realizaron entrevistas semiestructuradas (2) a diversas personas ligadas a la escuela más antigua que posee el barrio: docentes, directivos, porteros, ex alumnos, mujeres que enviaron a sus hijos a esa escuela, entre otros. Paralelamente, cada uno de estos cumple un rol diferente dentro del barrio como comerciantes, ex obreros ferroviarios, enfermeras y obreros jubilados, quienes traen a su memoria sus experiencias de vida. Sin dudas, este ejercicio es realizado desde una óptica subjetiva, pero no por ello menos involucrada en una historia global socio-cultural. En este mismo sentido, Paul Ricoeur expresa que entre el presente y la experiencia vivida se encuentra el tiempo relatado: "El tiempo humano es siempre un tiempo relatado". (1975: 14) El recuerdo y el olvido son condiciones necesarias que se cruzan con la impronta de sentidos que pone en juego el sujeto en el relato. "El objetivo es comprender los modos por los cuales el sujeto se produce y es producido como actor social" (Altabhe, Schuster, 1999).

Junto con las entrevistas anteriormente mencionadas, se utilizaron distintas fuentes documentales que permitieron no sólo reconstruir y establecer continuidades y rupturas en el proceso de configuración de la identidad barrial, sino también, dentro de los aspectos metodológicos del análisis, confrontarlas con los componentes de algunos documentos. Se plantearon elementos de la problemática sin sobre interpretar datos, que podrían conducir a conclusiones menos acertadas. En este sentido, el perfil de indagación metodológico permite poner al descubierto e identificar fenómenos latentes que en el "común de la gente" podrían quedar vedados. De esta forma, se busca, dentro de las evidencias que son compartidas por el sentido común, desentrañar la naturaleza de las representaciones, para elaborar elementos en relación con las causas que producen el fenómeno barrial en cuestión.

El procedimiento llevado a cabo, consistió en el abordaje de la historia del barrio enraizada en la dinámica social, teniendo presente la distinción entre los dos niveles de análisis: por un lado, una circunstancia singularizada que muestra una situación vivida por quien es entrevistado y por el otro, las condiciones históricas de existencia que sobre determinaron dicha situación, 
trabajando las experiencias relatadas y las problemáticas histórico sociales propias de esa época (Bensa, 1998).

Como se señaló al comienzo, se realizó un recorte circunscripto en espacio y tiempo: una zona del noroeste de la ciudad de Rosario, Barrio Belgrano, en la década de 1990. Recorte que resulta significativo puesto que este barrio se caracterizó por estar habitado principalmente por obreros pertenecientes al ferrocarril Mitre. Considerando esta particularidad, el objetivo se centra, entonces, en examinar el impacto que durante esos años tuvieron las políticas de privatización de las Empresas Estatales, su marca en el tejido social y sus alcances en la transmisión del legado cultural en la escuela. En primer término, se aborda el modo en que estos procesos de crisis fueron recepcionados, elaborados y puestos en escena, o no, por la escuela. En segundo lugar, se intenta indagar acerca de cuáles fueron las continuidades y rupturas que produjo el proceso de privatizaciones, afectando no sólo la configuración de la identidad sino también la formación de vínculos intersubjetivos del tejido social en el barrio y en la escuela seleccionada. Antes de adentrarnos en estos objetivos, conviene presentar algunas características del ferrocarril Mitre y una breve historización del Barrio Belgrano, cuestiones en este caso fundamentales para contextualizar y precisar luego el impacto de las políticas de estado durante los años noventa.

\section{Breve caracterización histórica de la expansión del ramal del ferrocarril Mitre}

Los trabajos de cimentación de los ferrocarriles en Argentina comienzan en la segunda mitad del siglo XIX. Las tareas de construcción y los capitales para poner en funcionamiento este medio de transporte, corrieron por cuenta de empresas británicas. La expansión de la red activó la creación de nuevos poblados y caminos, generando actividades productivas como el auge de la agricultura pampeana y la producción azucarera en Tucumán, entre otras. Este tramo ferroviario, el Mitre, se pone en funcionamiento a partir de 1870: recorre las provincias de Buenos Aires, Santa Fe, Córdoba, Santiago del Estero hasta llegar a Tucumán. Asimismo incluyó transportes de cargas y de pasajeros, algunos con servicios de lujo, constituyendo, junto a otros ramales ferroviarios, una de las rutas de mayor importancia dentro del país (Schvarzer, 1999).

En 1946 comienza el proceso de traspaso del ferrocarril de manos privadas al Estado argentino, efectivizándose dicha transferencia en 1947. El sistema ferroviario, ahora estatizado, reagrupó los ramales en seis líneas. A partir de ese momento, el ramal que atravesaba el barrio Belgrano, fue denominado Mitre. A fines de la década de 1950 se habían llegado a construir más de $40.000 \mathrm{~km}$. de extensión de vías. No obstante, comienza a notarse una suerte de proceso regresivo en lo relativo al sistema ferroviario de transporte: las condiciones de los ferrocarriles eran casi obsoletas debido a la antigüedad de los equipos y la falta de una logística moderna del sistema (Schvarzer, 1999). 
En las décadas del 50' y 60', la empresa se encuentra envuelta en un déficit que se irá incrementando de un modo notable, afectando directamente el presupuesto nacional. Por ejemplo, con el gobierno de Frondizi, en 1961, se pretende implementar el plan Larkin, que genera un retroceso en el desarrollo y construcción de vías, así como en las posibilidades de inversión en el sistema ferroviario. Este plan tenía como objetivo, en líneas generales, una larga serie de cancelaciones, cierres y desmantelamiento de vías. No puede llevarse a cabo en su totalidad, debido a una larga huelga obrera en oposición a la ejecución del mismo, que duró aproximadamente 42 días.

Con el golpe de Estado de 1966, encabezado por el general Juan C. Onganía, los ferrocarriles fueron militarizados a través del decreto $N^{\circ} 5324 / 69$, el cual criminalizaba las medidas de protesta. La intervención de sus sindicatos y el desguace de grandes extensiones de kilómetros de vías férreas, fueron dos características de este período. Posteriormente, durante la última dictadura militar (1976-1983), se pidieron créditos a nombre de estas empresas, hecho que produjo un engrosamiento de la deuda externa. La corrupción, el déficit fiscal, el endeudamiento y el vaciamiento, constituyen los elementos claves que señala Schvarzer (1999).

Durante las dos gestiones del gobierno de Carlos Menem (1989-1999), comienza a efectivizarse la Ley de Reforma del Estado, implementándose la privatización de las empresas estatales. La red vial de transporte de ferrocarril fue alcanzada por dichas reformas de corte neoliberal. A pesar de grandes movilizaciones y huelgas obreras, la privatización del ramal Bartolomé Mitre ya era un hecho hacia finales de 1992 (Schvarzer, 1999).

La publicidad en los medios de comunicación, promovió en la opinión pública el convencimiento que las empresas estatales eran las responsables del déficit fiscal. Asimismo se intentó mostrar los supuestos beneficios que traerían las entidades privadas, de cara a la burocracia y administración pública, en desmedro del Estado. Ante esta situación, no tardó en hacerse dominante la idea de que la prosperidad vendría por el lado de la desregulación estatal y la libertad del mercado. Con la cancelación y privatización de las prestaciones se vieron interrumpidos la mayoría de los servicios de pasajeros, disminuyendo notablemente las frecuencias hasta casi la total desaparición. (Schvarzer, 1999) Luego de dicha desnacionalización de las empresas estatales y con la convertibilidad como plan económico en marcha, la desocupación asciendió al $25 \%$ en la población económicamente activa.

\section{Identificación socio - histórica de un barrio que creció a la par del tren: "nombrar el barrio"}

¿Cuáles son las conjunciones y posicionamientos que implican a un individuo para identificarse con "ser del barrio"?, ¿esto se relaciona meramente con el hecho de vivir allí en un espacio físico o abarca una serie de aspectos 
históricos que hacen a la identidad barrial, a la pertenencia a un grupo social, a la vez que posibilita diferenciarlo de otros grupos sociales?, ¿cómo se mantiene la tradición, la pertenencia?, son algunos de los interrogantes que se suscitan para abordar la identificación socio histórica del barrio, es decir, para conceptualizar aquello que se designa como "nombrar el barrio".

Gravano (1991) propone pensar la historia de un barrio basándose en la identidad barrial, que se configuraría a partir de un doble movimiento de conjunción y disyunción. El primero establece los grados de homogeneidad e identificación y el segundo los niveles de heterogeneidad y diferenciación del barrio. Estos pueden observarse tanto en su interior, configurándose grupos diversos en donde puede predominar uno por sobre el otro; como en relación con otros sectores barriales de la ciudad.

El barrio Belgrano surge a fines del siglo XIX y principios del siglo XX. Quien fuera dueño de las tierras, Nicasio Vila, un importante terrateniente que luego sería intendente de esta ciudad, solicita a la municipalidad la creación del pueblo Eloy Palacios, nombre del anterior dueño de las tierras, otro reconocido potentado de la época.

A través de una ordenanza municipal de 1889 (3), se consigue el nombramiento, a modo de "nacimiento barrial", de un nuevo escenario socio cultural que será posteriormente integrado a la ciudad. Es importante destacar que, dentro de la ordenanza, se reconoce a este pueblo como parte integrante del municipio. Aunque la fisonomía de pueblo permitió cierta autonomía respecto del municipio de Rosario. A ello contribuyó la distancia y aislamiento que había, en ese momento, respecto a la gran ciudad.

En 1906 pasa a llamarse barrio Vila (4). A los cuatro años de este último decreto, en 1910, la Municipalidad de la ciudad de Rosario, en homenaje al Primer Centenario de la Revolución de Mayo (5), decide cambiar el nombre a una gran cantidad de barrios, entre ellos al barrio Vila. En este contexto, tomó el nombre de Barrio Belgrano, el cual conserva hasta la actualidad. La llegada de esta ordenanza municipal tuvo diferentes implicancias y efectos en los pobladores que se vieron afectados por ella: muchos de los nombres impuestos a los distintos barrios no prosperaron, por ejemplo el barrio Tiro Federal sería desde ese momento Moreno, Echesortu sería Alberdi. En los que sí se impuso el cambio fue en el barrio Mendoza (luego Azcuénaga) y en el barrio Belgrano.

Cabe destacar que este nombre impuesto arbitrariamente a través de una ordenanza municipal, tardó mucho en instalarse entre los vecinos del barrio, y actualmente es muy poco frecuente encontrar habitantes de la ciudad que lo reconozcan como Belgrano. En cambio, sí es reconocido por otras características: "el que tiene un cruce de avenidas" o "el de la calle Mendoza al 6500", dirección del centro del barrio.

Aunque resulte paradojal, la denominación "Vila", que fue en términos oficiales una designación que permaneció menos tiempo, perduró más en la 
memoria de sus pobladores. Ninguno de las tres nomenclaturas fue producto del acontecer propio del barrio, como en la historia de otros de la misma ciudad. Es interesante resaltar que el nombre Vila no sólo significa quien cedió las tierras, trazó y diseñó los orígenes del barrio: Vila también da nombre al edificio de una institución. Es la estación de trenes la que lleva la denominación de "Estación Vila" caracterizando la pertenencia a un sector social, a una forma de trabajo, como también de relacionarse subjetivamente, de establecer lazos sociales. A tal punto la estación fue una referencia del lugar que, si se observan los anuarios estadísticos de la municipalidad hasta los años 80', allí se denominaba al barrio directamente como Vila. En una de las entrevistas queda reflejada esta cuestión:

En los 40' como estaba el auge de la estación todavía lo usaban. Era la costumbre ya en el 70' era para todos barrio Belgrano. Las familias o gente que vivía cerca de la estación le seguía diciendo Vila. También lo identifican con las cuatro plazas. No asocian el lugar con el nombre, no lo conocen por el nombre. (vecino del barrio, octubre 29, 2010).

Existen relatos que plantean a la organización barrial en torno al trabajo, constituyéndose éste en ordenador de la vida intersubjetiva, enmarcando vínculos, estableciendo lazos sociales, amalgamando las relaciones y el tiempo libre.

La propiedad del barrio era la estación. Para el barrio la estación era lo máximo" (vecino del barrio, marzo 11, 2011).

Sesenta años atrás la gente lo había tomado como un paseo el ir a la estación a ver llegar el tren. Las chicas, los muchachos iban a ver llegar al vecino, siempre alguno venía en el tren. Era una costumbre, era lo más importante para el barrio (vecino ex- ferroviario, agosto 30, 2010).

La estación de trenes, perteneciente al Ferrocarril Mitre, lleva este nombre y hasta los años 70', según los pobladores, nadie lo conocía como barrio Belgrano, y en cambio sí era reconocido como barrio Vila, "el de la estación Vila". Este fue trascendental, dejó una impronta de sentidos en la mayoría de los pobladores. Puede que tal denominación, junto al debilitamiento de los ferrocarriles como empresa de transporte del Estado Nacional, su posterior privatización en la década de los 90', y la caída del prestigio social que gozaban los obreros ferroviarios, se haya opacado, haciéndose cada vez más invisible, cobrando fuerza la última denominación instituida de barrio Belgrano. La estación de trenes "Estación Vila," ahora abandonada a su suerte, es un testigo mudo de lo que fue la organización de la vida barrial.

Hoy se identifica al barrio como el "de las cuatro plazas", nombre habitual que se le da al parque Bartolomé Mitre, el cual consta de cuatro pequeñas pla- 
zas ubicadas en el centro neurálgico del barrio, constituyendo así su "pulmón verde". Además, contiene una rotonda de dos avenidas importantes para la zona, diseñadas desde el inicio del trazado de los planos.

\section{Divisiones geofísicas de la identidad barrial: territorio y territorialidad}

Promediando el año 1954, se designan los límites espaciales del barrio mediante una ordenanza (6): la calle Solís al este, la Avenida de Circunvalación al oeste, las vías del FFCC Mitre al norte y la calle Pasco al sur. Es importante mencionar que estos son los límites fijados una vez que el barrio se encontró integrado en su totalidad a la ciudad de Rosario.

Anteriormente, existía entre el barrio y la ciudad terrenos despoblados y hasta una laguna que luego se rellenó para la construcción de lo que hoy es un sector del barrio Azcuénaga. Al extremo oeste, se encuentra el barrio Empalme Graneros, también caracterizado por ser de trabajadores. En este sentido, el barrio con el correr del tiempo fue homogeneizándose con la ciudad a medida que ésta cobraba nuevas dimensiones. Aquello que no deja de ser distintivo es la voluntad con la que sus pobladores buscaron "tenerlo todo" allí, en el barrio:

Antes las distancias eran muchas y acá tenían todo, los quinteros, la capilla y después la escuela pública, bailes para los jóvenes en el Cosmopolita, el cine Roma, la fuente de trabajo, sumado a las tierras fértiles y el canal de agua, no podían no avanzar, tenían todo en el barrio. Con la instalación del ferrocarril y el tranway que conectaba con Rosario, la gente se empezó a quedar, todo estaba ahí y contenían a las familias. (maestra del barrio, noviembre 19, 2010). Yo no voy al centro porque acá también tengo todo en barrio Belgrano (vecina del barrio, noviembre 25, 2010).

Si bien la mayoría de sus pobladores reconocen las delimitaciones del barrio coincidiendo con la ordenanza municipal, en el límite norte hay diferencias: éste es reconocido con la Avenida Eva Perón, que es anterior a las vías del ferrocarril, reduciéndolo algunas cuadras. (Roulier, 2001, abril 16) (7) Éste, como se mencionó, fue un barrio de clase trabajadora conformado en su mayoría por obreros ferroviarios, que vivían allí por la cercanía con el taller que existió en la ciudad de Pérez. En la vecina localidad, se realizaba el arreglo de locomotoras y en el taller ubicado en Rosario se arreglaban coches y vagones. En sus orígenes, estos talleres hicieron necesaria la llegada de ingenieros, funcionarios y técnicos ingleses para los que se construyeron barrios para su alojamiento. Lo curioso es que del otro lado de aquella avenida, hacia el noroeste del barrio, se encuentra dispuesto el barrio Fisherton, donde sus primeros pobladores fueron estos ingleses que ocupaban cargos jerárquicos en la empresa de FFCC. 
Diferencias socio - económicas e históricas muy marcadas entre quienes viven de un lado y del otro de la avenida, se pusieron en juego. Como se anticipó, Fisherton estuvo ligado al ferrocarril, sólo que al ubicarse allí los ejecutivos de la empresa de transporte se delimitaron diferencias identitarias entre los barrios. Como una forma de marcar territorialidad, cada familia se ubicó en uno o en otro, dependiendo del lugar que ocupaba en los estamentos de la empresa estatal. El territorio, espacio geofísico, se convierte en territorialidad histórica y social tomando relieve y movimiento que demarca las idiosincrasias particulares de cada sector social que se "enfrenta" a sus diferencias.

Belgrano, entonces, está identificado por sus propios habitantes como un barrio de trabajadores: "El trabajo fue juntando a la gente acá" (vecino del barrio, agosto 18, 2010), manifiesta no sin cierto orgullo un vecino. Otros entrevistados esbozan el mismo parecer:

Era toda gente empleada en fábricas, empleados ferroviarios había muchos y como en Pérez estaba el taller y era bien cerquita, había muchos ferroviarios acá. (vicedirectora de la escuela $\mathrm{N}^{\circ} 91$, junio 10 , 2010)

Hace veintiocho años que trabajo acá. (...) En ese entonces la mayoría era ferroviario y ahora no, muchísimo cambió, en el grupo de cooperadora la mayoría eran ferroviarios, la mayoría. (...) En esa época colaboraban mucho más. (...) Mi hermano puso todos los cerámicos que vos ves, sábado a la tarde y domingo venían a trabajar, ahora no viene nadie" (portera de la escuela y ex miembro del club de madres de la escuela $N^{\circ} 91$, junio 9, 2010).

En el desarrollo del diálogo, en las entrevistas, surge como una constante la figura enaltecedora del trabajo. Mediante la construcción del discurso se remarca constantemente que el desarrollo de las relaciones intersubjetivas de la vida barrial se organizó en torno al mismo. Como por ejemplo: "No quería quedarse nadie atrás, si fulano hacía una vereda, el otro también. Uno le decía al otro: -¿por qué no hacés y yo te ayudo? No sabés lo que era sábado y domingo esto, cómo se trabajaba, se ayudaban, todos querían progresar, todos tiraban para arriba" (vecino del barrio, marzo 23, 2011).

El trabajo se constituyó, a su vez, como proyecto identificatorio, como anhelo y logro de la dignidad de una generación, ya que incluyó a los miembros de la comunidad en un espacio social propio y distintivo. En este sentido, puede decirse que un proyecto identificatorio es "el soporte de las identificaciones que [...] el sujeto debe encontrar en el discurso de su grupo de pertenencia, como referencias que le permitan proyectarse hacia un futuro" (Aulagnier, 1997: 159). Es decir, el trabajo se concibe como aquello que condiciona a la vez que aporta a la construcción de la identidad y los vínculos entre los pobladores del barrio. 
La identidad es entendida como un proceso de configuración continua, donde hay cambios y continuidades, producto de unidades contradictorias que se unen a la vez que se mantienen en contradicción y lucha. "Se va conformando tanto en cada individuo como en lo colectivo una totalidad de elementos que le permiten, a la comunidad y a cada uno de sus miembros, identificarse a la vez que diferenciarse (Racedo, 2004:21). Concebir la categoría identidad en estos términos, permite indagar en como se fue estructurando en este barrio inscripta en una continuidad histórica, y otorgarle sentidos a la memoria. A su vez, la identidad heredada, que es siempre social, se reproduce y modifica, dando lugar al proceso mediante el cual los movimientos de pérdida y recuperación, olvido y memoria producen el sentido de pertenencia. Esta, junto a la transmisión del legado cultural son la columna vertebral del proyecto identificatorio. (Forlini, 2010) El concepto de legado cultural como aquello que se transmite de una generación a otra, es puesto en funcionamiento no como una cuestión de simple transposición de formas tangibles cargadas de significados intrínsecos. Los sujetos en cuanto actores y redes de actores, tienden a inventar cultura, se refieren a ella, hacen experiencias con ella, la recuerdan, discuten sobre ella y, por lo tanto, la transmiten. (Hannerz, 1997) En suma, se concibe a la relación entre estas nociones como un movimiento mutuo, que realizan en forma incorporada; donde no hay uno y otro por separado sino que un concepto se encuentra en el otro y viceversa, condicionándose recíprocamente.

A pesar de que este barrio ha ido creciendo en cuanto al número de pobladores - principalmente debido a los movimientos de migración interna que afectaron a la ciudad, transformándola en una gran urbe - esto no fue impedimento para resguardar algunas costumbres propias de las poblaciones más pequeñas, en cuanto al devenir de lo cotidiano, como añoranzas de una época en que el lazo social era palpable y posible:

Por ahí voy caminando y me encuentro con uno, me pongo a hablar y le pregunto los apellidos y les digo, con un pariente tuyo fui a la escuela, o tomé la comunión, o jugué al futbol (...) Después con la tranquilidad que gozamos, se puede transitar libremente, casi como una cosa pueblerina, siempre nos encontramos con alguien conocido (vecino del barrio, octubre 29, 2010).

Usted veía que el vecino se sentaba ahí, que el chico estaba jugando, eso era una tranquilidad que ahora no la tenemos (vecina del barrio, agosto 12, 2010).

El proyecto identificatorio, según Aulagnier (1997), como búsqueda de un proyecto de vida a futuro, es sostenido y amparado por los fundamentos del enunciado del discurso del grupo de pertenencia, los cuales, a partir de su transmisión, ayudan a que una gran variedad de significados que se encuen- 
tran indiferenciados puedan reacomodarse en un todo organizado de sentidos. Procuran asegurar un "nosotros", garantizando "la supervivencia del grupo por el reparto entre los individuos de lo que les es común" (Debray, 1997: 20):

Todo se hizo con ayuda de los vecinos, en el año 35 ' se hizo la vecinal para pedir cosas para el barrio y esta misma Sociedad de Socorros Mutuos Cosmopolita, se hizo con mucho esfuerzo. Había como un sentido de pertenencia fuerte. Casi todo el barrio se hizo con el esfuerzo de la gente (vecino del barrio, marzo 11, 2011).

Ya en 1990, esta vida cotidiana comenzaba a desestructurarse y a producir efectos: con la creciente desocupación y las pérdidas de los puestos de trabajo el desmembramiento del tejido social comenzaba a sentirse en los pobladores del barrio. Se ha podido escuchar al respecto:

Sabe qué pensaba la gente, está bien que los rajen a los ferroviarios, son unos vagos bárbaros. La gente decía: mirá todo lo que ganan! que los rajen a todos, son una manga de vagos. Nos hacían una propaganda bárbara en la época de Menem, que daban pérdida que con esa plata se podían hacer quinientas escuelas y todo eso. Si yo no hubiera sido ferroviario y escuchaba todo eso y...decía que lo cierren" (vecino del barrio ex ferroviario, agosto 30, 2010).

La organización en torno al trabajo, principalmente el ferroviario, aquello que enlazaba las relaciones intersubjetivas, se fue fragmentando, se resquebrajaron aquellos enunciados simbólicos fundamentales para el desarrollo pleno del proyecto identificatorio del barrio: "Acá en el barrio había muchos metalúrgicos y ferroviarios que se fueron en la época de Menen. Mis sobrinos eran ferroviarios, cobraron la indemnización de veinte años, se fueron del barrio y no consiguieron más un trabajo seguro como el del ferrocarril" (vecina del barrio, agosto 19, 2010). En palabras de una maestra: "Vos veías pasar gente, gente, gente y te dabas cuenta que volvían de trabajar, Después cuando perdieron su trabajo... eso... eso fue un golpe muy duro a los trabajadores" (maestra, diciembre 16, 2010). Otra docente sostiene: "Se empezaron a ver comercios chiquitos, la gente abría muchos kiosquitos adelante, en el comedor" (maestra, diciembre 13, 2010).

Las formas de la vida cotidiana del barrio comenzaron a desmembrarse dando paso a una nueva estructuración de la vida cotidiana: "En esa época había abrazos solidarios a la escuela, había corte de calles porque estaban manifestando. Había concentraciones, vos pasabas por la estación y había movimiento, efervescencia, después hubo como una muerte" (maestra, noviembre $25,2010)$. Desaparece la manera en que se establecieron las lazos sociales del barrio, produciendo un quiebre en la continuidad de la construcción de la red 
social barrial. Su derivado fue el aislamiento de los vínculos intersubjetivos, junto al debilitamiento y desintegración de los soportes colectivos de la vida social.

\section{Acerca de la transmisión del legado cultural en la escuela: La Ley Federal de Educación de la década del 90'}

A raíz del proceso de reforma del Estado podría plantearse, por un lado, de qué modo se configuraron las prácticas de transmisión del legado cultural en la escuela del barrio, por el otro, cómo se reestructuró el trabajo cotidiano en las aulas, y asimismo, cómo se establecieron los vínculos intersubjetivos en el interior de la institución escolar y de ésta con la comunidad educativa en general.

Teniendo en cuenta los múltiples aspectos que se involucran y trastocan en momentos de crisis, los cuales impactan en lo identitario, se indagaron los efectos de las medidas políticas y económicas, principalmente las que tuvieron como objetivo adecuar el sistema educativo a las exigencias del nuevo modelo de estado neoliberal, propio de la década de los noventa.

En concordancia con las políticas de privatización y achique del estado, se implementó la Ley Federal de Educación (LFE) N² 24195, sancionada en 1993. Esta ley "culmina con una serie de debates y encuentros previos, [...] para dar lugar a una nueva estructuración de todo el Sistema Educativo Argentino" (Puiggrós, 1999: 42).

En aquel momento, las argumentaciones del gobierno oscilaban desde la necesidad de una reforma en el sistema en materia educativa, hasta el planteo de la sanción de esta ley como producto del consenso social y de la demanda de los docentes para el cambio (Puiggrós, 1999).

Mientras se descentralizaba totalmente el financiamiento económico de las instituciones educativas, buscando responder a las políticas económicas internacionales que imponían el Banco Mundial y el Fondo Monetario Internacional, se centralizaba y concentraban los contenidos y la formación, tanto de alumnos como de maestros, en el sistema jerárquico del estado. De hecho, la centralización se marcó a través de la sustitución en la denominación: de Escuela Primaria a Educación General Básica (EGB), agregando dos años más de obligatoriedad, el $8^{\circ}$ y el $9^{\circ}$.

Esta tendencia centralizante también tuvo su correlato en la implementación de los Contenidos Básicos Comunes (CBC) para la educación nacional, la capacitación docente a través de la Red Federal de Formación Docente Continua y la evaluación del sistema desde el Sistema Nacional de Evaluación de la Calidad de la Educación.

Las variaciones en materia de políticas educativas a causa del "achique" del Estado, se manifestaron, además, en un recorte de su responsabilidad como proveedor único de educación pública, para pasar a ser corresponsable con otros actores sociales, como por ejemplo las empresas, las familias y la Iglesia. Cabe destacar que, al no haber una ley provincial que adhiera a los principios 
de la Ley Federal, las reformas anteriormente mencionadas, se materializaron a través de decretos, normativas y circulares que proliferaron ante la ausencia de una ley unificadora (Cardini y Vedela, 2002).

Junto a la notable reducción en el financiamiento, invade la narrativa educativa, toda una nueva terminología dando lugar a una oleada de nuevos vocablos y expresiones semánticas que se expandieron en las escuelas y discursos de docentes y directivos. Alguno de ellos son: PEI (Proyecto Educativo Institucional), PCl (Proyecto Curricular Institucional), TEBE (Transformación Educativa Basada en la Escuela), etc. Desde esta perspectiva, se tergiversarían viejas demandas del sector que conjugadas con una nueva jerga las altera y modifica sustancialmente. Así se presenta el juego de doble discurso: de reivindicar y hacer lugar a viejas demandas en educación por un lado, y quedando relegadas las vías reales de implementación, sólo al lugar de la nueva retórica plasmada en documentos y decretos; por el otro (Puiggrós, 1999).

Las maestras de la escuela del barrio seleccionada, expresan como fue la experiencia de presenciar los efectos en los procesos sociales y colectivos mencionados con anterioridad, como por ejemplo la desocupación: "Vivimos la década de los 90' muy afectados por las familias de los chicos. Se vivió con mucha angustia, conteniendo a las familias, lo que te contaban los chicos. Hubo en todos los grados y en todos los grupos algún desocupado" (maestra, noviembre 19, 2010). Otra docente sostiene: "Y acá en la escuela lo que se notó es que cambió el rol de la familia. La mamá y el papá salieron los dos a trabajar y eso se prestó a que el chico se maneje solo" (maestra de grado, diciembre 13, 2010).

Las prácticas escolares cobraron otra dinámica y en este sentido, se agregaron nuevas actividades vinculadas con aspectos burocráticos, como por ejemplo, armar el PEl y el PCl. Al mismo tiempo se redujeron otras. A aquellas vivencias se le suman las que se producen directamente como consecuencia de la reforma educativa, dentro de la organización escolar y en sus actores, maestros y alumnos: "Fue muy duro, muy duro porque los tiempos corrían y había cosas que teníamos que cumplir. (...) De ahí empezó una decadencia importante da la sensación de un camino sin retorno (...) es como que no te podés recuperar" (maestra de grado, diciembre 13, 2010). "La escuela sufrió. Para el primer ciclo fueron unos años... eso repercutió un montón en la enseñanza" (maestra de grado, noviembre 25, 2010).

Asimismo se planificaron nuevas estrategias didácticas, el trabajo en las aulas se reestructuró: "Nos afectó mucho, no se pedían libros, nada, pedíamos dos moneditas para la fotocopia y yo también fotocopiaba (...) estuvo fea la situación" (maestra de grado, diciembre 13, 2010). "Me acuerdo que hacíamos los libros acá" (maestra de grado, noviembre 25, 2010).

La no exigencia de gastos económicos fue una forma de atenuar las preocupaciones que atravesaban las familias de la comunidad educativa. Como 
un abordaje casi espontáneo, a nivel institucional, de la crisis económica que imperaba en el barrio, pero también en muchas zonas de la ciudad y el país. Tampoco las vivencias relatadas dan cuenta de la implementación de vínculos con otras escuelas o con el gremio, para paliar la crisis, ni hay referencias a la puesta en práctica de programas o proyectos institucionales, más o menos formales, tendientes al fortalecimiento del cuerpo docente para el abordaje de la situación. El trabajo docente no era dimensionado como una conformación grupal: proliferaba el sentimiento de retraimiento, una suerte de sensación de soledad e indefensión frente a las circunstancias de la crisis, obligados los docentes a afrontar por cuenta propia las contingencias, arrojados a asumir las responsabilidades ajenas, como queda de manifiesto en las entrevistas realizadas:

Empezó todo lo del 'pobrecito', pero por otro lado, se venía toda la situación social y se dejaban pasar muchas cosas por lo social, tampoco que te resbalaba lo que pasaba, es que uno no es de palo. Se decía, y bueno, lo veremos el año que viene, lo desarrollo en otro momento. Faltaban cosas, había que pedir lo menos posible, trabajar con lo que podías (maestra de grado, noviembre 25, 2010).

La ejecución y adaptación de la provincia a la Ley Federal de Educación no fue inocua, produjo profundos cambios en esta escuela, en tanto irrumpe en la historia institucional y por ende en la tarea docente, actuando como estímulo disruptivo que trastoca modificando sustancialmente componentes que hacen a la cotidianeidad escolar. $Y$ es ese contenido inexpugnable de otras épocas, que pierde terreno y resulta ser expulsado o reemplazado por nuevas concepciones dentro del universo simbólico del grupo de pertenencia escolar y de los maestros. Cuando se produce esa transmutación, el significado queda excluido, como si nunca hubiese sido inscripto en el discurso del conjunto.

Por último, se observa también en las entrevistas anteriores, como el impacto de las políticas de privatización de los años noventa penetró, en los cánones culturales en la escuela, de forma tal que obturó estilos institucionales que hacían a la transmisión histórica del legado cultural barrial.

Esa radical denegatoria de una herencia arrinconada en el pasado, que fuera atesorada en otro momento histórico, tiene como derivación inevitable, que parte de la historia a ser transmitida, trascienda en el devenir el olvido y la marginalidad de la memoria. $Y$ todo aquello que no se encuentra integrado y reconocido por el grupo de pertenencia, no puede llegar a ser legítimo. El corolario de este planteo trasunta en un rechazo o indiferencia hacia un significante, otrora consagrado como lo característico, aquello que marca a fuego todo lo que perteneció a la identidad del barrio (Hassoun, 1996).

Se plantea un legado cultural, que los niños de las nuevas generaciones no reciben, produciendo efectos en sus identidades. Los efectos de las políticas 
de privatización, como la privación a las nuevas generaciones de participar de un proyecto identificatorio producto del vínculo histórico entre el sujeto y su grupo de pertenencia. Sin un legado, se disuelven los vínculos de dependencias tradicionales, se pierde la transmisión del saber hacer, las creencias y las normas. Podríamos hablar hasta de un sujeto desafiliado, que no está inscripto en ningún sistema social colectivo, sin descendencia, sin historia, producto de la individuación; ¿producto de nuevas certezas?

\section{A modo de reflexión final}

Como una primera síntesis de este trabajo abordado desde la perspectiva de la microhistoria socio-cultural educativa del barrio Belgrano de la ciudad de Rosario, es necesario presentar algunas reflexiones.

Se escogió un recorte en el tiempo -la década de los 90'- en el que se analiza un conflicto a nivel macro social y cómo éste se plasma a nivel micro social. Hasta aquí se examinó cómo un período histórico repercute en el tejido social dejando profundas huellas que trastocan los pilares básicos de la identidad del barrio y su gente. La década del 90' sería un punto de inflexión en el desarrollo histórico del discurso del conjunto social del barrio estudiado.

Es en este período histórico en el que se produjo una reestructuración muy fuerte a nivel macro con la privatización de los ferrocarriles y la pérdida de los puestos de trabajo, de la cual el barrio no quedó exento de sus consecuencias. En este sentido, se trastocaron en profundidad los múltiples espacios organizativos de quienes habitan este barrio: el trabajo, la familia, la escuela, la vecinal.

Para examinar la configuración de la identidad de un barrio, resulta imprescindible tener como herramienta de análisis la contextualización en el espacio y en el tiempo. Esto no es sólo el "telón de fondo" en donde transcurre una escena, sino que se torna ineludible para dar sentido a los acontecimientos sucedidos en tanto condicionante directo de las acciones y decisiones de los sujetos y las organizaciones involucradas. Así, en este juego de pesos y contrapesos entre el individuo y la sociedad, en el devenir histórico, se va forjando la figura de aquello que se asume como identidad: construida, lograda, o en cierto modo impuesta, aggiornada en cada sujeto de acuerdo a ingredientes diferentes de una misma receta. Ello rompe con la idea sustancialista de identidad que es dada esencialmente, desde siempre y por lo tanto inmodificable.

La cultura como proceso de producción y reproducción de bienes simbólicos de una comunidad, engendraría en ese mismo proceso la transmisión del legado cultural a las nuevas generaciones. Esa transmisión, nunca lineal ni neutral, se encuentra cargada de implicancias subjetivas y sociales haciendo que de ningún modo se reproduzca miméticamente.

Aquello que se habría producido en el barrio Belgrano, es un quiebre impuesto en la continuidad, del proceso de transmisión del patrimonio cultural de la vida cotidiana. Hay una ruptura obligada del legado histórico en la memoria 
social del lugar, que deviene una nueva forma de constituir la misma, producto de la fractura en los roles y labores. Las formas de vida barrial, comienzan a desmembrarse abruptamente para pasar a una nueva estructuración. Desaparece la manera en que se establecieron los lazos solidarios como construcción de una red en común. Su derivado fue el debilitamiento y la desintegración de los soportes colectivos que articularon a los actores sociales, originando el aislamiento de los vínculos intersubjetivos. Este sería un proceso de desmantelamiento de las organizaciones para pasar a una re - organización de las relaciones inédita hasta entonces en el barrio y la escuela.

Si se retoman las experiencias de las maestras en su conjunto, que fueron presentadas en este texto, surge claramente que las políticas de privatización marcaron de manera contundente el quehacer de la escuela y sus actores. Mas aún, la reforma educativa provincial implementada a partir de la Ley Federal de Educación habría operado, conjuntamente con las políticas de Reforma del Estado, en una profunda destrucción de la identidad de la organización educativa estudiada y de los sujetos involucrados en ella. En otras palabras, este proceso habría impactado directamente en la escuela del barrio dando lugar a una inscripción reconfiguradora de las identidades docentes y la organización escolar. La crisis alcanzaría el complejo representacional de la escuela originando una estructuración no explorada, a la vez que inédita en relación a las organizaciones escolares, su legado y su identidad.

Sucede entonces que esta sutil dialéctica de la memoria y del olvido se derrumba y la historia entera es alcanzada por la pérdida, la negación o la nostalgia. Esa radical denegatoria de un ciclo arrinconado en el pasado, que fuera atesorado en otro momento histórico, tiene como derivación inevitable, que parte de la identidad barrial a ser transmitida, trascienda en el devenir el olvido.

El triunfo del olvido, deja el sabor amargo de haber salteado un capítulo en la construcción del pasado posible a través de las vivencias. Y la certeza de vivir en la nostalgia de lo cotidiano, por parte de los sujetos integrantes de una comunidad ferroviaria, sabiendo que aquella negación o pérdida, es una forma de defensa para cubrirse de un período superado y al que no hay retorno probable, trasunta en que parte de la historia pueda ser contada mas no transmitida.

\section{Notas Bibliográficas}

(1) Este trabajo es una versión revisada y ampliada de una comunicación presentada en las VI Jornadas Nacionales "Espacio, Memoria e Identidad", realizadas los días 29 y 30 de junio y $1^{\circ}$ de julio del año 2011 , en la ciudad de Rosario.

(2) Las entrevistas se realizaron con una guía de preguntas a modo de orientación del entrevistador, aunque ello no fue un impedimento para que el entrevistado pueda explayarse en sus respuestas.

(3) Digesto Municipal: Ordenanza del 11 de junio de 1889. Art. 10: Apruébese la traza del pueblo que va a fundar el señor Nicasio Vila bajo el nombre de "Eloy Palacios" en el 
paraje que expresa en el plano de referencia. Art. $2^{\circ}$ - El concesionario por sí y los propietarios que le sucedan en adelante estarán obligados a acatar y cumplir las ordenanzas vigentes y las que en lo sucesivo se dictaren, pues dicho pueblo formará parte integrante de este municipio, no importando la aprobación otorgada ningún derecho ni prerrogativa que altere ni disminuya los efectos legales de las ordenanzas que emanen de este Honorable Concejo.

(4) Digesto Municipal: Decreto N²5. Año 1906.

(5) Digesto Municipal: Ordenanza N²8. Año 1910.

(6) Digesto Municipal: Ordenanza N¹338. Año 1954.

(7) Roulier, S (2001, abril 16). La tradición de vivir en Belgrano. La Capital, p.6.

\section{Referencias Bibliográficas}

- $\quad$ Althabe, G., Schuster, F. G. (Comps.). (1999). Antropología del presente. Buenos Aires: Edicial. [1 ${ }^{a}$ ed.fr. 1992]

- $\quad$ Aulagnier, P. (1997). La violencia de la interpretación. Del pictograma al enunciado. Argentina: Amorrortu.

- $\quad$ Bensa, A. (1998). Da micro-história a uma antropología crítica. En: Revel, Jacques (Org.). Jogos de escalas. A experiência da microanalise. (pp. 151-172) Rio de Janeiro: Editora da Fundação Getúlio Vargas.

- Bedarida, F. (1998). As responsabilidades do historiador expert. En: Boutier, J. e Dominique, J. Passados recompostos (pp. 145-153). Río de Janeiro: Editora UFRJ-FGV.

- Cardini, A. Vedela, C. (2002) Las provincias educativas. Estudio comparado sobre el Estado, el poder y la educación en las 24 jurisdicciones Argentinas. Buenos Aires. Cippec.

- Debray, R. (1997). Transmitir. Buenos Aires: Manantial.

- Forlini, N. (2010) La configuración de la identidad de los sectores populares en la era de la globalización. Apuntes para pensar las prácticas escolares, en Revista de la Escuela de Ciencias de la Educación. Año 6 N7, (pp. 175 - 189). ISSN 1851-6297. Rosario, Laborde Editor.

- Franco, M y Levin, F. (2007). El pasado reciente en clave historiográfica. En: Franco, M. y Levín, F. (comps.) Historia reciente. Perspectivas y desafíos para un campo en construcción. (pp. 31-65). Buenos Aires: Paidós.

- Gravano, A. y Guber R. (1991). Barrio sí, villa también. Buenos Aires: Biblioteca Política Argentina.

- Hannerz, U. (1997) Fluxos, Fronteiras e Híbridos: Palabras-chave da Antropología transnacional. Mana. 3 (2): (pp 7-39). ISSN 0104 -9313.

- Hassoun, J. (1996). Los contrabandistas de la memoria. Buenos Aires: Ediciones de la Flor.

- $\quad$ Nora, P. (1972) O retorno do fato. En: Le Goff, J. e Nora, P. Historia: Novos problemas. Río de Janeiro: Editora Francisco Alves.

- Puiggróss, A. (1999). Qué pasó en la educación argentina. Desde la conquista hasta el menemismo. Buenos Aires: Kapeluz.

- $\quad$ Racedo, J. [et al] (2004). Patrimonio cultural e identidad. Culturas populares, memoria social y educación. Buenos Aires: Cinco.

- $\quad$ Ricoeur, P. (1975). El tiempo relatado. La cultura y el tiempo (pp.11-15). España: Ediciones Siqueiro y Unesco. 
- Rosental, P. (1998). Construir o "macro" pelo "micro": Freddrik Barth e a "microstória". En: Revel, J. (Org.). Jogos de escalas. A experiência da microanalise. (pp. 151-172) Rio de Janeiro: Editora da Fundação Getúlio Vargas.

- Schvarzer, J. (1999). Los ferrocarriles de carga en la Argentina. Problemas y desafíos en vísperas del siglo XXI. Buenos Aires: Centro de Estudios Económicos de la Empresa y el Desarrollo (CEEED).

- Traverso, E. (2007). Historia y memoria. Notas sobre un debate. En: Franco, M. y Levin, F. (comps.) Historia reciente. Perspectivas y desafíos para un campo en construcción. (pp. 67-96). Buenos Aires: Paidós.

\section{Fuentes Documentales}

Diario La Capital: Roulier, S (2001, abril 16). La tradición de vivir en Belgrano. La Capital, p.6. Digesto Municipal: Ordenanza del 11 de junio de 1889.

Digesto Municipal: Decreto № 25. Año 1906.

Digesto Municipal: Ordenanza № 28. Año 1910. 